Following an initial pilot study, recipients were invited to complete a short online questionnaire and provide feedback to allow refinement of the provision.

Results: Respondents were asked a series of questions, each on a scale of 1-5. Every respondent gave a score of 5 in response to "What do you think of the idea of $A$ Little Box Of Hope?"

Every parent of children under ten years old gave a score of 5 for every item when asked "How useful is each item in your Little Box Of Hope?" Respondents also gave free-text comments:

* "It was very well thought out and I felt supported"

* "I know so much more about JIA now than I did before. I cannot thank you enough."

* "It was extremely useful and made me feel supported during a very stressful time and this enabled me to support my son more effectively."

* "It made my daughter feel less alone."

Some parents of older children felt that some information specifically for teens would be useful, and a Teen pack is being developed.

Conclusion: Recipients of $A$ Little Box Of Hope have found the information useful and feel supported. Following the pilot study, we have developed My JIA, a booklet reviewed by a multi-disciplinary clinical team, with comprehensive information for families affected by JIA. A Teen pack, for children aged around 10 years or older, is being developed to provide targeted support to this group.

The COVID-19 pandemic has adversely affected access to healthcare services, increasing the need for remote parent- and charity-provided support through $A$ Little Box Of Hope.

As such, we intend to expedite the roll-out of the project across the country building on the success of the pilot project.

REFERENCES:

[1] McErlane F, Foster HE, Carrasco R, et al. Trends in Paediatric Rheumatology Referral Times and Disease Activity Indices over a Ten-Year Period among Children and Young People with Juvenile Idiopathic Arthritis: Results from the Childhood Arthritis Prospective Study. Rheumatology (Oxford) 2016;55(7):1225-34

[2] Foster HE, Scott C, Tiderius CJ, et al. Improving Musculoskeletal Health for Children and Young People - A "Call to Action". Best Pract Res Clin Rheumatol 2020;34(5):101566.

[3] Dejaco C, Alunno A, Bijlsma JWJ, et al. Influence of COVID-19 Pandemic on Decisions for the Management of People with Inflammatory Rheumatic and Musculoskeletal Diseases: A Survey among EULAR Countries. Ann Rheum Dis 2020;0:1-9.

Disclosure of Interests: None declared

DOI: 10.1136/annrheumdis-2021-eular.2332

\section{OP0279-PARE CHRONIC RHEUMATIC DISEASE (CRD) AND SPORT}

P. Lemesle ${ }^{1}$, L. Poulain ${ }^{2}$, X. Grapton ${ }^{3}$, N. Bouhedja ${ }^{2}$ on behalf of CREER. ${ }^{1}$ Hospital of Courbevoie, Clinic Rives de Seine, Courbevoie, France; ${ }^{2} \mathrm{La}$ Garenne-Colombes, Private practice, La Garenne-Colombes, France; ${ }^{3}$ Neuillysur-Seine, Private practice, Neuilly-sur-Seine, France

Background: In order to study the state of mind of patients with chronic inflammatory rheumatic disease (CRD) regarding physical/sports activity, excluding household activities despite their quantifiable energy value (MET), the CREER group produces this study.

Objectives: Analyze a population in the lle-de-France region with CRD practicing a physical activity (their motivations, expectations, nature and rhythm). Determine the place of physical activity in the management of an CRD by the rheumatologist (Rh)

Methods: 207 patients, 53 yo average, 56\% between 50 and 70 years, $60 \%$ are women; $97 \%$ of the CRD, Rheumatoid arthritis (RA): $57 \%$ ) or Ankylosing Spondylitis (AS): $40 \%$, low or moderate activity (66\%).

10 years evolution (RA) and 11.5 years (AS), corticosteroids RA/AS as follows $(34 / 5 \%)$, NSAIDs (15/52 \%), conventional DMARDS $(84 / 30 \%)$ or biotherapies (21/43\%).

Co-morbidities are found for RA/AS in $55 \%$ vs $44 \%$, includes high blood pressure $20 \%$, overweight $21 \%$, tobacco $13.5 \%$, other $19 \%$.

Results: $7 / 10$ patients are encouraged to engage in physical activity, regardless of gender, age, RA or AS. The most common activity proposed is walking (53\%), followed by swimming and/or aquagym (40\%) and gym (19\%). The practice is regular in $60 \%$ more by women, $\mathrm{RA}=\mathrm{AS}$, more before 40 yo and after 60 years old $(70 \%)$. The activity actually practiced is: 1 - walking $46.4 \%$, 2- aquatic activities $37 \%$, 3- cycling 29\%, 4- home sports $19 \%$.

Once/week minimum is good for cycling and swimming, insufficient for walking, very good for sport at home.

$50 \%$ have been practicing for 3 years. $60 \%$ adapt the rhythm to rheumatism. Their motivations are: to maintain one's health, to de-stress.

A discordance exists between Rh/General physician that advise sport 8 times/10 vs $4.5 / 10$. Nevertheless $50 \%$ ignore whether he or she is getting worse or better, hence the need for information.
Rh needs to communicate more about the interest of physical activity and the absence of deleterious effect on CRD which one patient over two ignores.

If $60 \%$ of patients modify their activity with CRD, many do not participate in sports because no time, no need, no desire RA=AS.

If the activity is supervised, adapted, prescribed is well-known, its application is confidential due to lack of coaches, and of qualified centers.

Conclusion: If the main activity practiced by patients and advocated by $\mathrm{Rh}$ is walking, the patients go beyond this framework by mobilizing for cycling, walking, swimming and gym. But the reluctance persists and we must, through therapeutic education convince of the benefits of the activity on CRD and its co-morbidities, unknown to $50 \%$ of patients. To map lesions, judge the ability and desires are necessary to set goals for duration and frequency of activity. Using connected tools improves compliance. Finally, walking which does not require neither schedule nor equipment (otherwise a cane) should become a first-line prescription.

Disclosure of Interests: None declared.

DOI: 10.1136/annrheumdis-2021-eular.866

\section{OP0280-PARE A MINDFULNESS PROGRAM DOSING STUDY TO EVALUATE IMPROVEMENT IN EMOTIONAL DISTRESS AMONG PEOPLE WITH RHEUMATIC DISEASE}

J. Thompson ${ }^{1}$, N. Parikh ${ }^{1}$, K. Gavigan ${ }^{1}$, S. Venkatachalam ${ }^{1}$, W. B. Nowell ${ }^{1}$. ${ }^{1}$ Global Healthy Living Foundation, Patient Centered Research, Upper Nyack, United States of America

Background: Mindfulness-based interventions for chronic pain and emotional distress have increased in popularity as complementary therapies among people living with rheumatic and musculoskeletal disease (RMD). ${ }^{1,2}$ Despite growing evidence that mindfulness meditation reduces pain and anxiety associated with $\mathrm{RMD}$, more research is needed to specify the optimal duration of mindfulness training necessary to be effective for short- and long-term benefit.

Objectives: To evaluate and compare the effectiveness of full-length versus brief mindfulness training programs for improving anxiety among people living with RMD.

Methods: Adult US participants (pts) within the ArthritisPower registry were invited to participate in the Healthy Mind Healthy You study comparing the effectiveness of two online mindfulness training programs of different lengths accessed via the MoodNetwork platform. The full-length mindfulness based cog nitive therapy program lasted 8 weeks, while the brief evidence-based mindfulness program lasted 3 weeks. Pts were randomized to one of the two programs and completed assessments every two weeks during the program and then every four weeks during the 12-week follow-up period. Assessments included World Health Organization-Five Well-Being Index (WHO-5), Five Facet Mindfulness Questionnaire (FFMQ), Perceived Stress Scale (PSS), and two measures of emotional distress, PROMIS Short Forms for Anxiety and Depression. Analyses compared demographic characteristics and assessment scores by program length.

Results: 324 pts completed assessments at baseline and 70 pts completed them at week 8 , an attrition rate of $78 \%$ in each of the program arms. The majority of pts were female, White, with $67 \%$ between the ages of $45-64$ years. No statistically significant differences were observed at baseline between participants randomized to each of the two programs, and in their assessment scores at week 8 (Table 1); PROMIS Anxiety and Depression scores improved from baseline to week 8 for pts in both programs (Figure 1). Overall, mean (SD) PROMIS Depres sion scores improved from $58.4(7.7)$ at baseline to $55.4(7.2)$ at week $8(p=0.018)$ a meaningfully important difference, among the 70 pts reporting scores at both time points.

Table 1. Assessment Scores at Baseline and Week 8, Mean (SD)

\begin{tabular}{|c|c|c|c|c|c|c|c|c|}
\hline & \multicolumn{4}{|c|}{ Baseline } & \multicolumn{4}{|c|}{ Week 8} \\
\hline & $\begin{array}{c}\text { All } \\
(n=324)\end{array}$ & $\begin{array}{c}8 \text {-week } \\
\text { course } \\
(n=163)\end{array}$ & $\begin{array}{c}3 \text {-week } \\
\text { course } \\
(n=161)\end{array}$ & p-value & $\begin{array}{c}\text { All } \\
(n=70)\end{array}$ & $\begin{array}{c}\text { 8-week } \\
\text { course } \\
(n=35)\end{array}$ & $\begin{array}{c}\text { 3-week } \\
\text { course } \\
(n=35)\end{array}$ & p-value \\
\hline WHO- $5^{b}$ & $\begin{array}{l}10.6 \\
(4.9)\end{array}$ & $10.4(4.8)$ & $10.9(5.0)$ & 0.378 & $\begin{array}{l}12.0 \\
(5.1)\end{array}$ & $12.5(5.5)$ & $11.6(4.7)$ & 0.488 \\
\hline $\mathrm{FFMQ}^{\mathrm{c}}$ & $\begin{array}{l}42.7 \\
(6.1)\end{array}$ & $42.7(6.1)$ & $42.7(6.1)$ & 0.932 & $\begin{array}{l}39.2 \\
(5.7)\end{array}$ & $38.9(6.1)$ & $39.4(5.3)$ & 0.741 \\
\hline PSS $^{d}$ & $18.7(7.5)$ & 19.2 & $18.3(8.2)$ & 0.304 & $\begin{array}{l}16.6 \\
(7.3)\end{array}$ & $15.7(7.8)$ & $17.6(6.8)$ & 0.291 \\
\hline $\begin{array}{l}\text { PROMIS } \\
\quad \text { Depression }^{\text {e }}\end{array}$ & $\begin{array}{l}56.5 \\
(8.3)\end{array}$ & $57.3(8.0)$ & 55.7 (8.6) & 0.097 & $\begin{array}{l}55.1 \\
(8.5)\end{array}$ & $54.8(9.3)$ & $55.5(7.8)$ & 0.735 \\
\hline $\begin{array}{l}\text { PROMIS } \\
\text { Anxiety }^{\dagger}\end{array}$ & $\begin{array}{l}58.7 \\
(8.2)\end{array}$ & $59.0(8.2)$ & $58.4(8.1)$ & 0.470 & $\begin{array}{l}55.4 \\
(7.2)\end{array}$ & $54.6(7.4)$ & $56.1(7.1)$ & 0.404 \\
\hline
\end{tabular}

${ }^{a}$ denotes use of Fisher's Exact Test ${ }^{\mathrm{b}}$ Range 0 (worse) to 25 (better), ${ }^{\mathrm{c}}$ Range 3 (worse) to 15 (better), ${ }^{\mathrm{d}}$ Range 0 (better) to 40 (worse), ${ }^{\mathrm{e}}$ Range 24.7 (better) to 63.5 (worse), ${ }^{\mathrm{f}}$ Range 25.7 (better) to 62.0 (worse) 